Journal of

Accident and

Emergency

Medicine 1994

11, 204-205

\title{
The externally rotated leg: anterior dislocation of the hip
}

\author{
D.P.GWYNNE JONES \& R.N. VILLAR
}

Department of Orthopaedic Surgery, Addenbrooke's Hospital, Cambridge

\section{SUMMARY}

A case report of anterior dislocation of the hip presenting as a fractured neck of femur following a minor fall in an elderly patient.

Key words: anterior, dislocation, hip

\section{INTRODUCTION}

Anterior dislocation of the hip is a rare injury and usually results from a significant force. We describe a case occurring in an elderly lady following a minor fall.

\section{Case report}

An 89-year-old lady presented to the accident and emergency (A\&E) department following a fall in a nursing home, after which she was unable to weight bear on her left leg. She was deaf and demented with no other past history of note. She was usually mobile with a frame.

On examination her left leg was shortened and externally rotated. The hip was tender and any hip movement was painful. This suggested a fracture of the proximal femur. However radiographs showed an anterior dislocation, of the pubic type, with an associated small acetabular fracture. Manipulation under anaesthetic was required to achieve a satisfactory reduction; the position eventually being held in a plaster hip spica.

\section{DISCUSSION}

Correspondence: D.P. Gwynne Jones, Registrar, Department of Orthopaedic surgery, Dunedin Hospital, Dunedin, New Zealand
Anterior dislocation of the hip is rare, comprising only $10 \%$ of all hip dislocations. ${ }^{1,2}$ The patient demonstrated the pubic type of dislocation where the mechanism of injury is usually forcible abduction of the hip in extension. ${ }^{3}$ This generally requires significant force, such as a car striking a pedestrian from behind, ${ }^{4}$ although a case is reported as occur- ring while playing association football. ${ }^{5}$ As a result, the injury is usually seen in the younger, active agegroups. There are no reports of anterior dislocation in the elderly following a minor fall.

The usual position of the leg is in external rotation often with abduction and flexion. On clinical examination it thus may mimic a proximal femoral fracture. The appearances on a plain A.P. radiograph may not be obvious at first glance (see Fig. 1). If no fracture is seen, careful scrutiny and a good lateral view are needed if this rare injury is not to be missed.

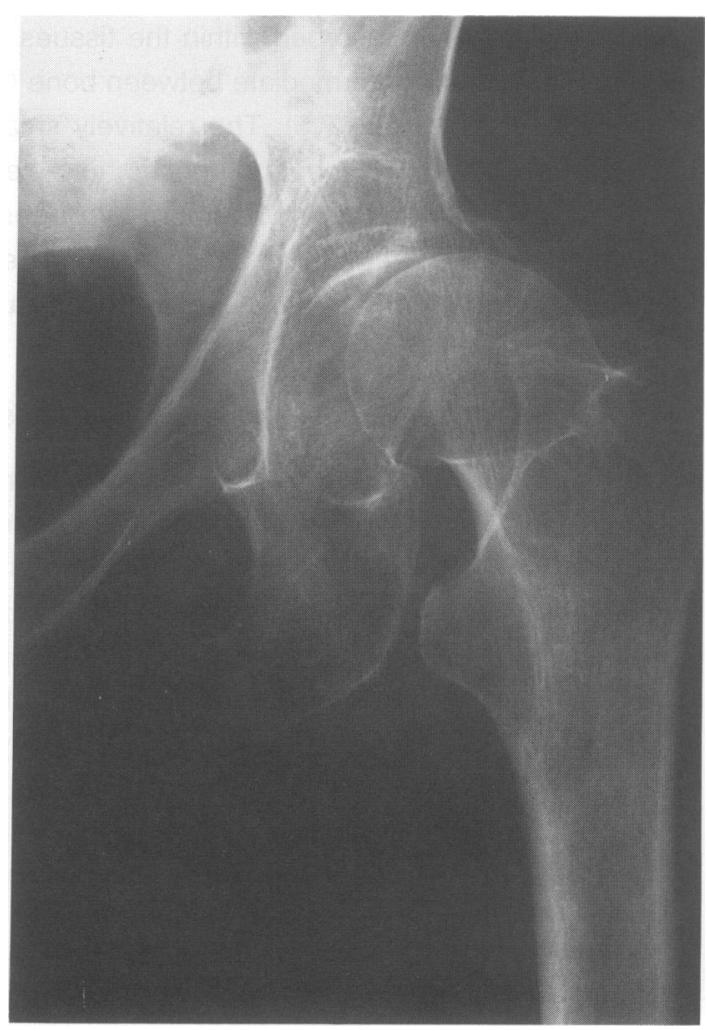

Fig. 1. Anteroposterior $X$-ray demonstrating loss of joint congruity with small superolateral acetabular lip fracture and rotation of the femoral head. 
The externally

rotated leg

\section{REFERENCES}

1. Epstein H.C. (1973) Traumatic dislocations of the hip. Clinical Orthopaedics and Related Research 92, 115.

2. Brav E.A. (1962) Traumatic dislocation of the hip. Army experience and results over a 12-year period. Journal of Bone and Joint Surgery (American) 44A, 1115.

3. Epstein H.C. \& Harvey J.P. (1972) Traumatic anterior dislocations of the hip. Management and results. Journal of Bone and Joint Surgery (American) 54A, 1561.

4. Amihood S. (1975) Anterior dislocation of the hip. Injury 7, 107.

5. Henderson R.S. (1951) Traumatic anterior dislocation of the hip. Journal of Bone and Joint Surgery (British) 33B, 602. 